Revista Perspectivas Online: Exatas \& Engenharia Dezembro/2021, v.11, n.34, p. 1 - 17 ISSN: 2236-885X (Online)

DOI: $10.25242 / 885 X 113420212477$

\title{
ESTUDO DA INFLUÊNCIA DA MICROSSÍLICA NO CONCRETO AUTO ADENSÁVEL
}

\author{
Yasmim Nathalie Carvalho Costa ${ }^{1}$, Thais Araujo Pinto ${ }^{1}$ \& Ayrton Hugo de Andrade e \\ Santos $^{1 *}$
}

\section{RESUMO}

SANTOS, A. H. A .; PINTO, T. A.; COSTA, Y. N. C. Estudo da influência da microssílica no concreto auto adensável. Estudo da influência da microssílica no concreto auto adensável. Perspectivas Online: Exatas \& Engenharia, v.11, n. 34, p. 1-17, 2021.

O concreto auto adensável (CAA) é definido como aquele capaz de fluir, preencher a forma, passar por elementos embutidos (dutos, armaduras e insertos), e auto adensar-se pelo seu próprio peso, dispensando qualquer meio de vibração externa ou adensamento, ao mesmo tempo que mantém sua homogeneidade, nas etapas de produção, transporte, assentamento e acabamento. Nos últimos tempos ele ganhou um importante papel na construção civil, principalmente com o crescimento do uso do sistema construtivo de paredes de concreto. Esse concreto tem sido estudado por diversos pesquisadores, com o intuito de melhorar o seu desempenho e a microssílica que é um pó fino com esferas de diâmetro $0,1 \mu \mathrm{m}$ e 5,5 $\mu \mathrm{m}$, considerada uma adição mineral altamente pozolânica pode contribuir com esses resultados. Assim, com o intuito de analisar a influência da microssílica no concreto auto adensável, este trabalho propõe estudar a adição de $3 \%, 9 \%$ e $15 \%$ de microssilica no concreto em relação à massa de cimento. Para tanto foram realizados testes no estado fresco e endurecido do concreto, conforme apresentado na metodologia deste trabalho. Os resultados confirmam que a adição de até $15 \%$ de microssílica tende a aumentar a resistência à tração e à compressão do concreto auto-adensável, sendo indicado seu uso.para a qualificação do concreto auto adensavel.

Palavras-chave: Análise Experimental; Concreto Auto adensável; sílica.

\footnotetext{
${ }^{1}$ Pontifícia Universidade Católica de Minas Gerais - PUC Minas - Departamento de Engenharia Civil, Instituto Politécnico IPUC - Av. Dom José Gaspar, 500, Coração Eucarístico, Sala 208A - prédio 10 Belo Horizonte, MG, Cep 30535-901, Brasil. 


\title{
STUDY OF THE INFLUENCE OF MICROSILICA ON SELF-COMPACTING CONCRETE
}

\author{
Yasmim Nathalie Carvalho Costa ${ }^{1}$, Thais Araujo Pinto ${ }^{1}$ \& Ayrton Hugo de Andrade e \\ Santos $^{1 *}$
}

\begin{abstract}
SANTOS, A. H. A .; PINTO, T. A.; COSTA, Y. N. C. Study of the influence of microsilica on self-compacting concrete. Perspectivas Online: Exatas \& Engenharia, v.11, n. 34, p. 117, 2021.
\end{abstract}

The Self-Compacting Concrete (SCC) is defined as that which is able to flow, to fill the form, to pass through embedded elements (ducts, reinforcement and inserts), to be self compactable by its own weight, dispensing with external vibration or densification while maintaining its homogeneity in the stages of production, transport, laying and finishing. This concrete has in recent times gained an important role in civil construction, especially with the growth in the use of the concrete wall construction system. This concrete has been studied by several researchers, in order to improve its performance and microsilica, which is a fine powder with spheres of $0.1 \mu \mathrm{m}$ and $5.5 \mu \mathrm{m}$ in diameter, considered a highly pozzolanic mineral addition can contribute to these results. Thus, in order to analyze the influence of microsilica in selfcompacting concrete, this work proposes to study the addition of 3,9 and 15 percentages of microsilica in concrete. To this end, tests were performed in the fresh and hardened state of the concrete, as presented in the methodology of this work. The results showed that the microsilica up to $15 \%$ tends to increase the tensile and compressive strength of self-compacting concrete, and its use is indicated.

Keywords: Experimental Analysis; self-compacting concrete; silica.

\footnotetext{
${ }^{1}$ Pontifícia Universidade Católica de Minas Gerais - PUC Minas - Departamento de Engenharia Civil, Instituto Politécnico IPUC - Av. Dom José Gaspar, 500, Coração Eucarístico, Sala 208A - prédio 10 Belo Horizonte, MG, Cep 30535-901, Brasil. 


\section{INTRODUÇÃO}

O concreto é um compósito formado por agregados miúdos, graúdos e aglomerantes e com o avanço dos estudos tecnológicos diversos outros materiais tem sido inseridos nele melhorando suas propriedades (DA SILVA, BONFIM, 2019). A microssilica é um destes materiais que tem sido incorporado nos concretos convencionais.

A microssílica é um pó fino com esferas de diâmetro entre $0,1 \mu \mathrm{m}$ e 5,5 $\mu \mathrm{m}$, considerada uma adição mineral altamente pozolânica (RILEM,1988), e é obtida do resíduo da indústria metalúrgica, conforme indicado por Mehta e Ramachandran (1984). Por ter características aglomerante na presença de umidade, a microssílica é muito utilizada na substituição de uma parte do cimento em concretos e argamassas, permitindo produzir concretos com ultradesempenho, conforme relatado por Mousavinejad e Sammak (2022).

A microssílica reage com o hidróxido de cálcio, $\mathrm{Ca}(\mathrm{OH})_{2}$, subproduto que é gerado durante a hidratação do cimento (ANJOS et al, 2016), e juntos formam os compostos silicatos e aluminatos de cálcio que são estáveis e muito aglomerantes (SANTOS, 1992). Outra característica importante é que a sílica age como microfiller no concreto, porque suas partículas são aproximadamente 5 a 100 vezes menores que as partículas do cimento, o que propicia que a sílica preencha os espaços entre as partículas de cimento (NBR 13956, 2012). Este efeito garante a homogeneidade dos produtos da hidratação do cimento no concreto.

Esse processo resulta em melhoria de algumas características do concreto, como a resistência à compressão, a resistência à tração, a reologia em estado fresco, a permeabilidade e o menor consumo de cimento, conforme indicado por Mielenz apud Santos (1992) e posteriormente comprovado por Golaszewska e Giergiczny (2021), que utilizaram a microssilica com adição de agregados calcários. Além disso, uma grande vantagem do uso da sílica ativa na construção civil é a utilização de um material que seria descartado no meio ambiente, representando sustentabilidade.

De acordo com Sabir (1995), Malhotra e Mehta (1996), Aitcin (1998) e, mais recentemente Wang et al. (2021) e Sumathi e Saravana (2022), o intervalo ideal de substituição de microssílica em relação à massa de cimento no traço de concreto e argamassa é de $7 \%$ a $10 \%$, sendo $16 \%$ considerado o limite máximo para essa substituição. A partir dessa porcentagem, as vantagens como o aumento da resistência à compressão são pouco significativas quando comparadas ao prejuízo relacionado às características de fluidez e trabalhabilidade.

Com o intuito de analisar a influência da microssílica no concreto auto adensável, uma vez que as maiorias do trabalhos apresentam qualidades da microssilica no concreto convencional, este trabalho propõe estudar as variações do comportamento mecânico do concreto auto adensável com o aumento percentual do teor de microssílica no composto, em relação à massa de cimento. Para tanto, foram realizados testes no estado fresco e endurecido do concreto.

Persp. Online: exatas \& eng., Campos dos Goytacazes, 34(11) 01 -17-2021 


\section{METODOLOGIA}

\subsection{Concreto auto adensável}

O concreto auto adensável (CAA) é definido como aquele capaz de fluir, preencher a fôrma, passar por elementos embutidos (dutos, armaduras e insertos), e auto adensar-se pelo seu próprio peso, dispensando qualquer meio de vibração externa ou adensamento, ao mesmo tempo que mantém sua homogeneidade, nas etapas de produção, transporte, assentamento e acabamento (NBR 15823-1:2017). O concreto auto adensável vai de encontro com o que é proposto por Salgado et al. (2019), no intuito de uso de novas tecnologias para gerar um maior grau de industrialização da construção civil.

No entanto, o concreto ao ser lançado na estrutura, tende a ter obstáculos, que favorece a segregação, com isso um cuidado com a mistura deve existir para que não gere problemas. Neste sentido, o CAA deve ser avaliado por meio de diversos ensaios ainda no estado fresco, com o intuito de verificar tais parâmetros.

De acordo com NBR 15823-1 (2017) e NBR 15823-2 (2017), para o concreto autoadensável no estado fresco, deve-se executar o ensaio de slump flow test; tempo de escoamento pelo método do funil V (relacionado com a viscosidade do material); habilidade passante (capacidade de escoar por entre as armaduras sem fibração mecanica ou manual) pelos métodos do anel $\mathrm{J}$ e da caixa $\mathrm{L}$; e resistência à segregação pelo método da coluna de segregação. A Figura 1 obtida do trabalho de Mendes et al (2017) mostra os respectivos equipamentos utilizados para os ensaios descritos.

Quando se busca o uso do CAA com função estrutural, as propriedades mecânicas do concreto endurecido ganham maior destaque, devendo ser analisadas com parcimônia para que possa ser utilizado na construção civil (DOMONE, 2006). Os principais parâmetros que são analisados são a resistência mecânica (tração e compressão), o ensaio de deformação, o ensaio de absorção e o índice de vazios.

Persp. Online: exatas \& eng., Campos dos Goytacazes, 34(11) 01 -17-2021 


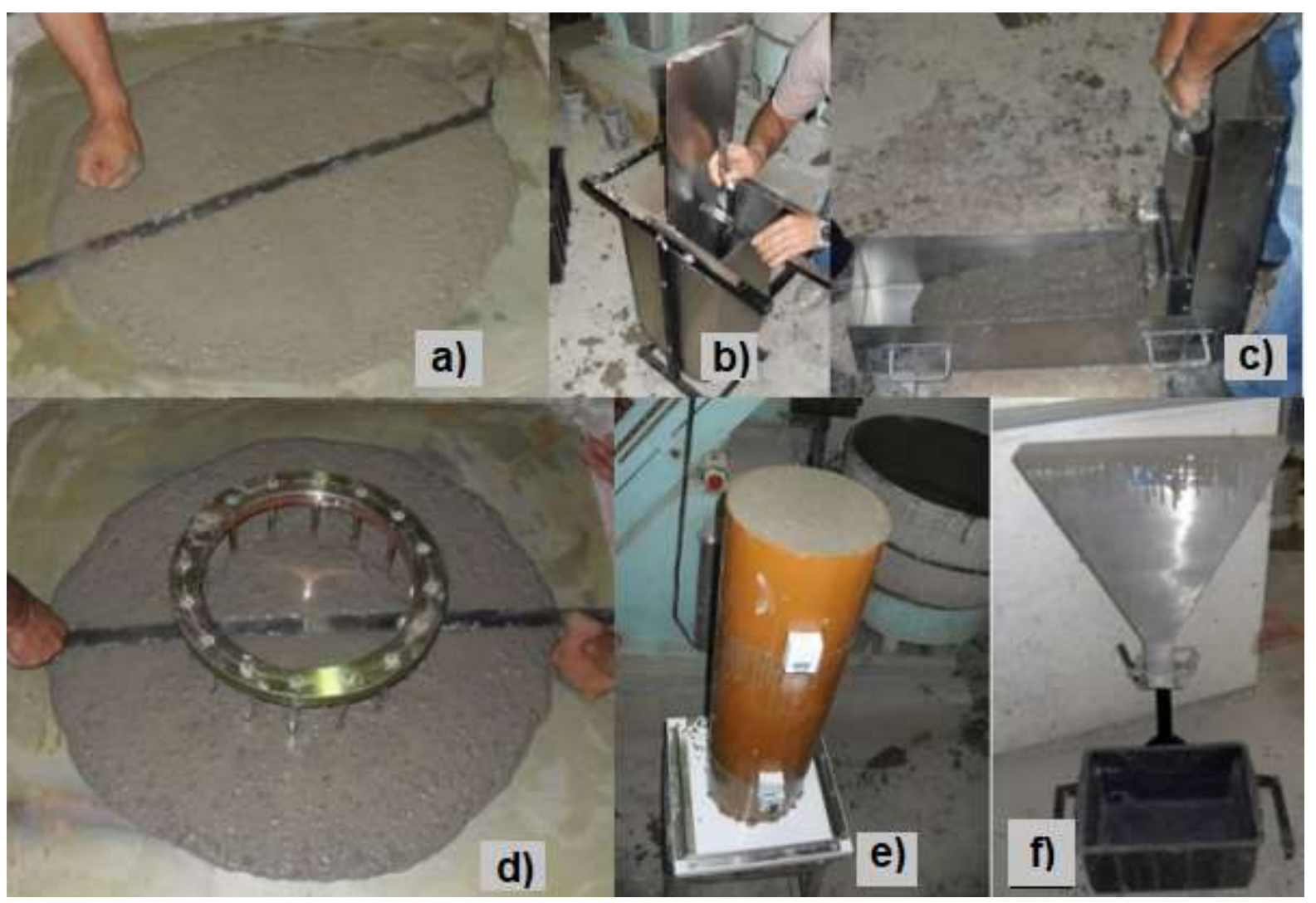

Figura 1: Métodos de ensaios para o concreto auto adensável no estado fresco: a) método do Cone de Abrams - slump flow; b) método da caixa U; c) método da caixa L, d) método do anel J; e) método da coluna de segregação; f) método do funil V.

De acordo com Klug e Holchmacher (2003) e Troyan e Kindras (2021), o CAA apresenta propriedades diferentes dos concretos convencionais em função das alterações na sua composição, uma vez que é adicionada uma maior quantidade de finos a mistura, com menor diâmetro dos agregados graúdos. Além disso, com a maior quantidade de finos no concreto, ocorre alterações na microestrutura do mesmo, levando a um menor índice de vazios e consequentemente uma maior densidade. Por fim, Troyan e Kindras (2021) afirmam que as modificações na quantidade de pasta de cimento no CAA, gera um aumento da resistência à tração do concreto.

\subsection{Microssílica}

A microssílica é um material pozolânico cujas partículas possuem diâmetro entre 0,1 $\mu \mathrm{m}$ e $5,5 \mu \mathrm{m}$, que é muito menor que a dimensão das partículas de cimento. Além disso, a microssílica é um material aglomerante na presença de água, o que permite sua utilização em concreto e argamassa como substituição de uma parte do cimento (NBR 13956, 2012).

A utilização da microssílica como parte do material aglomerante do concreto garante benefícios como o aumento da resistência à compressão e o aumento da resistência à tração, a depender do teor de sílica utilizado em relação à massa de cimento (MIELENZ apud SANTOS, 1992).

Wang et al. (2021) e Sumathi e Saravana (2022) estudaram os efeitos da microssílica nas características químicas, físicas e mecânicas do concreto. Nestes estudos foram realizados experimentos científicos que comprovam os benefícios da sílica no concreto além da melhoria

Persp. Online: exatas \& eng., Campos dos Goytacazes, 34(11) 01 -17-2021

https://ojs3.perspectivasonline.com.br/ 
da resistência mecânica. Outras melhorias observadas foram o aumento da homogeneidade dos produtos da hidratação do concreto, a redução da permeabilidade, o menor consumo de cimento e a melhoria da reologia do concreto em estado fresco. Nestes trabalhos concreto de ultra-alta-resistencia foram alcançados.

Nos trabalhos de Sabir (1995), Malhotra e Mehta (1996), Aitcin (1998), Wang et al (2021) e Sumathi e Saravana (2022) foi possível observar uma convergência dos resultados, podendo então concluir que o intervalo ideal para o teor de substituição de cimento por sílica no concreto é entre $7 \%$ e $10 \%$ e o teor máximo de substituição é de $16 \%$.

Sabir (1995) afirma que de acordo com os experimentos realizados, o teor máximo de sílica no concreto deve ser de 16\%. Posteriormente Malhotra e Mehta (1996) obtiveram resultados que os levaram a definir que o intervalo ideal para o teor de sílica no concreto é entre $7 \%$ e $10 \%$ e que o teor máximo de sílica é $15 \%$. Dois anos após esse estudo, deu continuidade a esses estudos e definiu o intervalo de teor de sílica entre $8 \%$ e $10 \%$ em relação à massa de cimento. Mais recentemente Wang et al. (2021) e Sumathi e Saravana (2022), para a produçaõ de concretos de ultra-alta-resistência utilizaram um percentual de $11 \%$ de microssilica.

A determinação de um teor máximo de sílica é importante porque em concretos autoadensáveis com teores de sílica superiores a essa porcentagem não há ganho significativo de resistência mecânica e, além disso, pode acarretar na redução da fluidez e da trabalhabilidade do CAA, o que seria prejudicial.

\subsection{Programa experimental}

Inicialmente, utilizando o método de dosagem da Associação Brasileira de Cimento Portland $(\mathrm{ABCP})$, foi calculado o traço de concreto a ser utilizado para o estudo. Esse método de dosagem não leva em consideração a adição de superplastificante, mas o traço obtido pelo método foi utilizado apenas como referência. Para esse traço de referência buscou-se atingir uma resistência característica à compressão (fck) de $25 \mathrm{MPa}$.

Com base nos trabalhos de Wang et al. (2021) e Sumathi e Saravana (2022) foram elaborados quatro dosagens de CAA, variando a porcentagem de microssílica considerando os intervalos definidos pelos autores citados na revisão bibliográfica. As porcentagens utilizadas foram $0 \%, 3 \%, 9 \%$ e $15 \%$, sendo que a dosagem sem adição de microssílica foi adotada como a traço de referência, como citado.

Para produzir o concreto autoadensável foi utilizado aditivo superplastificante na quantidade de $3 \%$ da massa de cimento. Esse percentual está dentro da faixa prescrita pelo fornecedor que é de $0,5 \%$ a $3 \%$ da massa de cimento. Com os parâmetros definidos o traço calculado teve a proporção de 1,0:1,74:2,65:0,5. A Tabela 1 apresenta as dosagens utilizadas com a respectiva nomenclatura adotada.

Os materiais utilizados na confecção do concreto autoadensável para os traços indicados na Tabela 1 foram:

- $\quad$ Cimento Portland de Alta Resistência Inicial. CP V- ARI;

- $\quad$ Microssílica (diâmetro 0,1 $\mu \mathrm{m}$ e 5,5 $\mu \mathrm{m}$ );

- Aditivo superplastificante Power 400, utilizado para reduzir a quantidade de água, aumentando a fluidez e resistência;

Persp. Online: exatas \& eng., Campos dos Goytacazes, 34(11) 01-17-2021

https://ojs3.perspectivasonline.com.br/ 
- Areia média lavada, com grãos de diâmetro entre $0,42 \mathrm{~mm}$ e $2 \mathrm{~mm}$, $\delta=1.470 \mathrm{~kg} / \mathrm{m}^{3} ;$ (Curva granulometrica apresentada na Figura 2).

- $\quad$ Brita 1, com malha entre $9,5 \mathrm{~mm}$ e $19 \mathrm{~mm}, \delta=1.500 \mathrm{~kg} / \mathrm{m}^{3}$; (Curva granulometrica apresentada na Figura 3).

- $\quad$ Água potável.

Tabela 1: Traços do Concreto auto adensável utilizados nas moldagens.

\begin{tabular}{|c|c|c|c|c|}
\hline Materiais & CAA 3 & CAA9 & CAA15 & CAAO \\
\hline Cimento (10kg) & 1,000 & 1,000 & 1,000 & 1,000 \\
\hline $\begin{array}{l}\text { Areia natural } \\
\qquad(10 \mathrm{~kg})\end{array}$ & 1,738 & 1,738 & 1,738 & 1,738 \\
\hline Brita $(10 \mathrm{~kg})$ & 2,651 & 2,651 & 2,651 & 2,651 \\
\hline $\begin{array}{c}\text { Aditivo } \\
\text { superplastificante }\end{array}$ & 0,03 & 0,03 & 0,03 & 0,03 \\
\hline $\begin{array}{c}\text { Relação } \\
\text { água/cimento }\end{array}$ & 0,500 & 0,500 & 0,500 & 0,500 \\
\hline Microssílica & $\begin{array}{l}3 \% \text { da massa } \\
\text { de cimento }\end{array}$ & $\begin{array}{l}9 \% \text { da massa de } \\
\text { cimento }\end{array}$ & $\begin{array}{l}15 \% \text { da massa } \\
\text { de cimento }\end{array}$ & $\begin{array}{l}0 \% \text { da massa } \\
\text { de cimento }\end{array}$ \\
\hline
\end{tabular}

Abertura das peneiras ( $\mathrm{mm}$ )

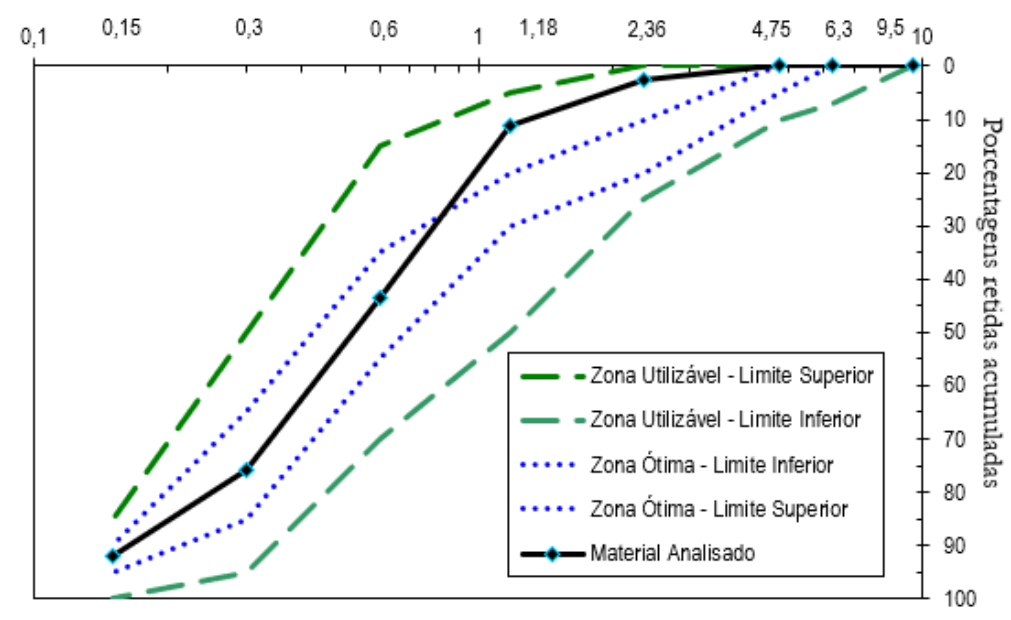

Figura 2: Curva granulometrica da areia média lavada

Para as 4 dosagens de CAA foram realizados os ensaios de Slump-flow, no concreto ainda no estado fresco, conforme especificação da NBR 15823-2:2017. No concreto endurecido foram realizados os ensaios mecânicos seguindo as prescrições normativas da NBR 5739 (2018) tendo sido moldados um total de 14 corpos de prova de $100 \mathrm{~mm}$ de diâmetro e $200 \mathrm{~mm}$ de altura, para cada dosagem, perfazendo um total de 56 corpos de prova no trabalho. Foram realizados o ensaio de resistência à compressão, o ensaio de resistência à tração indireta (compressão diametral). Além disso foi realizado o ensaio de densidade dos concretos utilizando a Equação 1. 


$$
\rho_{\text {Corpo de prova }}=\frac{m}{V_{\text {Corpo de prova }}}=\frac{m}{h \times \pi \times r^{2}} \frac{(\mathrm{kg})}{\left(\mathrm{m}^{3}\right)}
$$

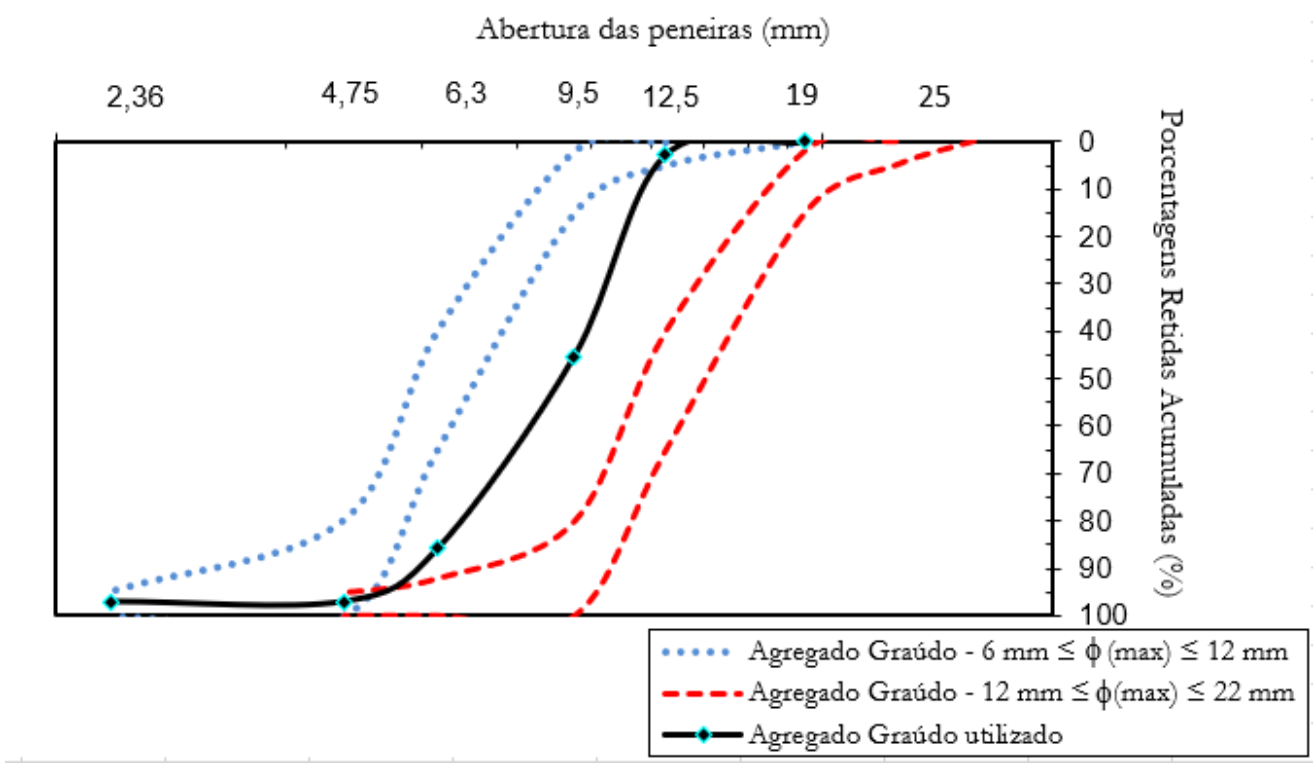

Figura 3: Curva granulometrica da brita 1

\section{RESULTADOS E DISCUSSÕES}

\subsection{Concreto no estado fresco}

Durante a concretagem foi aferido o espalhamento do concreto no estado fresco através do ensaio de Slump-flow, conforme mostrado na Figura 4.

A Figura 4-a mostra que o concreto de referência, ou seja, sem adição de microssílica apresentou boa fluidez, alcançando um espalhamento de $700 \mathrm{~mm}$, dentro do limite de referência. O concreto com adição de 3\% também apresentou baixa segregação e boa espalhabilidade, cerca de $560 \mathrm{~mm}$, conforme é possível identificar na Figura 4-b. Esse valor foi abaixo do traço de referência, mas está dentro dos limites prescritos por norma, como mostrado na Tabela 2. O concreto com 9\% de microssílica, mostrado na Figura 4-c, avaliando qualitativamente em relação aos dois anteriores, apresentou as melhores características visuais esperadas para o concreto autoadensável, aparentando baixa segregação e boa espalhabilidade, na faixa de $650 \mathrm{~mm}$.

Já o concreto com $15 \%$ de microssílica apresentou baixa viscosidade e maior segregação que os demais, sendo um indício que o aumento elevado da microssílica reduz a propriedade de fluide do compósito. O espalhamento deste concreto foi de apenas $480 \mathrm{~mm}$ (Figura 4-d).

A norma NBR 15823-2:2017 estabelece os limites de espalhamento e as respectivas classificações conforme mostrado na Tabela 2. Os resultados obtidos para os 4 traços confeccionados estão presentes na Tabela 3.

Tabela 2: Classes de espalhamento segundo o ensaio Slump-flow

\begin{tabular}{ccc}
\hline Classe & Espalhamento $(\mathrm{mm})$ & Método de ensaio \\
\hline
\end{tabular}

Persp. Online: exatas \& eng., Campos dos Goytacazes, 34(11) 01-17-2021 


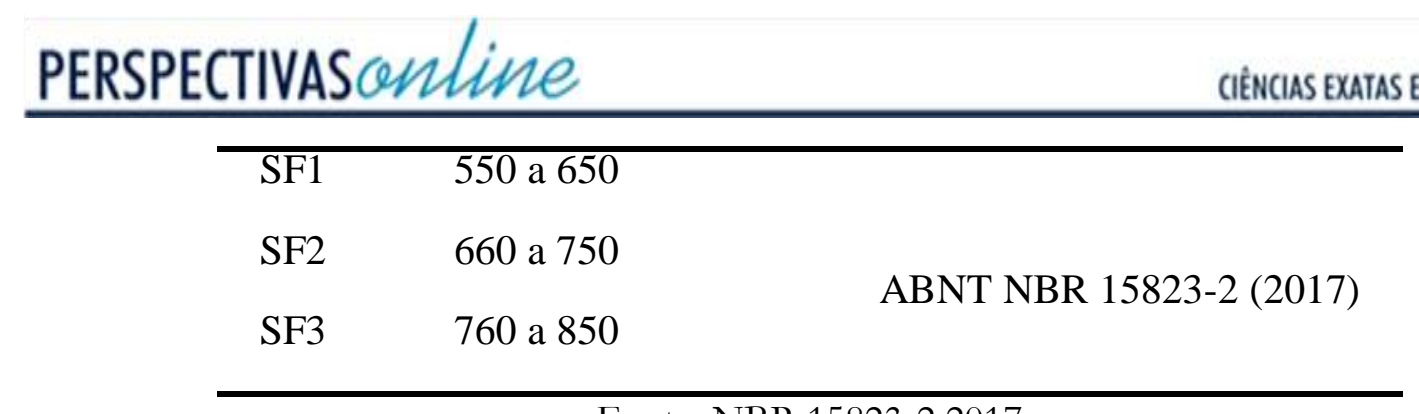

Fonte: NBR 15823-2:2017

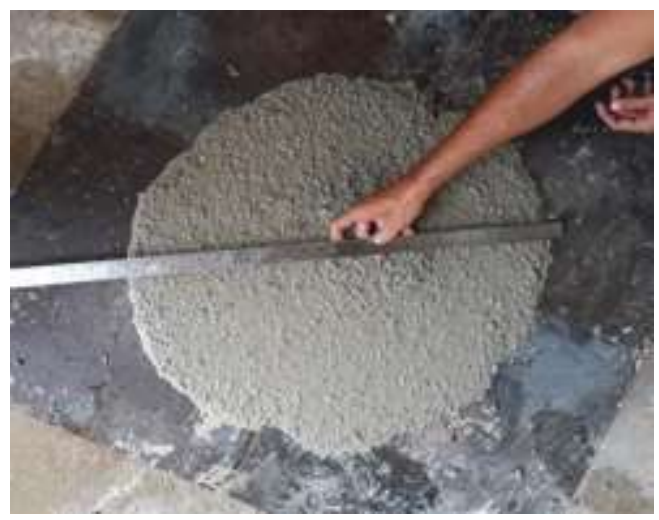

(a)

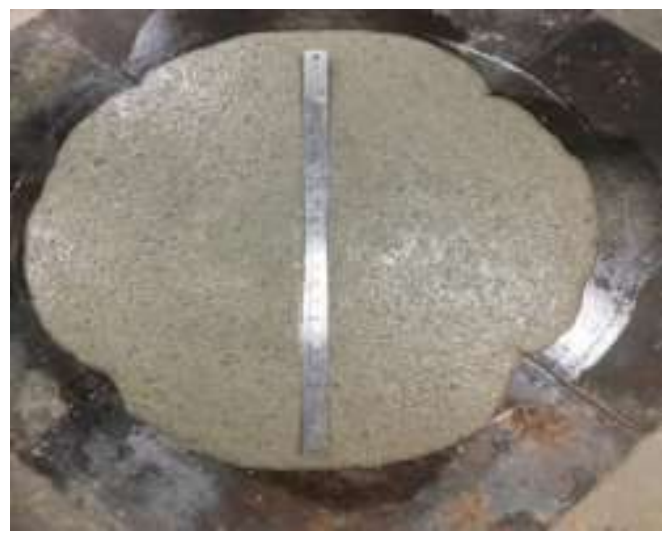

(c)

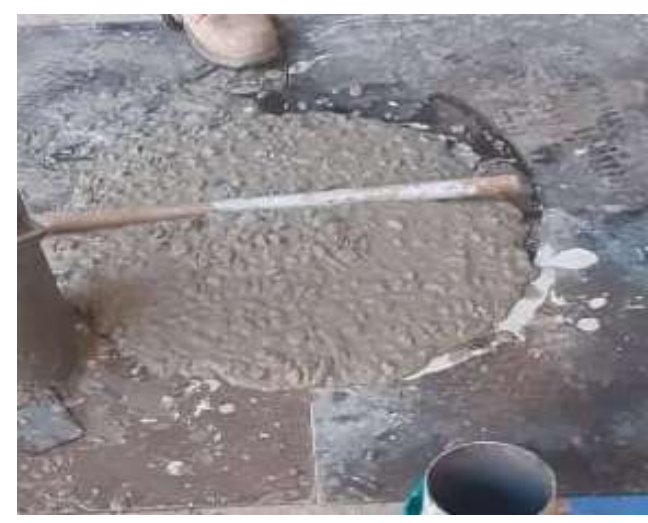

(b)

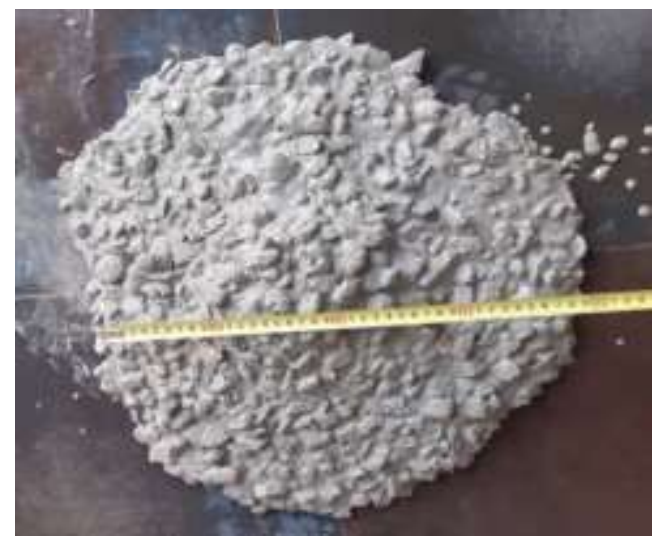

(d)

Figura 4: Ensaio de Slump-Flow para o CAA0 (a), CAA3 (b), CAA9(c), CAA15 (d)

Tabela 3: Resultados obtidos no ensaio Slump-flow

\begin{tabular}{cc}
\hline Dosagem & Espalhamento $(\mathrm{mm})$ \\
\hline CAA0 & 700 \\
CAA3 & 560 \\
CAA9 & 650 \\
CAA15 & 480 \\
\hline
\end{tabular}

Persp. Online: exatas \& eng., Campos dos Goytacazes, 34(11) 01-17-2021 https://ojs3.perspectivasonline.com.br/ 
Observa-se que o espalhamento do traço de referência CAA0 atendeu os limites da norma, ele está entre os limites de $660 \mathrm{~mm}$ e $750 \mathrm{~mm}$ sendo classificado como SF2. Os traços CAA3 e CAA9 classificam-se como SF1, pondendo ser utilizados em diversas aplicações como lajes, revestimento de túneis, estacas e fundações. O resultado do traço CAA15 não se classifica em nenhum dos intervalos estabelecidos pela norma, apresentados na Tabela 2, já que obteve-se espalhamento inferior a $550 \mathrm{~mm}$, que é o menor valor dos intervalos.

\subsection{Concreto no estado endurecido}

\subsubsection{Compressão axial}

Na Tabela 4 são apresentados os resultados dos ensaios de compressão axial realizados nos corpos de provas dos concretos auto-adensáveis para as idades de 7 e 28 dias.

Tabela 4- Resultado à compressão axial à 7 e 28 dias

\begin{tabular}{lllll}
\hline Traço & $\begin{array}{l}\text { Resistência à } \\
\text { Compressão média } \\
\text { (MPa) }\end{array}$ & $\begin{array}{l}\text { Diferença (\%) em } \\
\text { relação ao traço de } \\
\text { referência } \\
\mathbf{7} \text { dias }\end{array}$ & $\begin{array}{l}\text { Resistência à } \\
\text { Compressão } \\
\text { média (MPa) } \\
\mathbf{2 8 ~ d i a s ~}\end{array}$ & $\begin{array}{l}\text { Diferença (\%) em } \\
\text { relação ao traço } \\
\text { de referência } \\
\text { 28 dias }\end{array}$ \\
\hline CAA0 & 13,81 & 0,00 & 18,96 & 0,00 \\
CAA3 & 14,62 & 5,86 & 24,13 & 27,26 \\
CAA9 & 30,87 & 123 & 49,45 & 160,81 \\
CAA15 & 19,22 & 39,17 & 34,48 & 81,84 \\
\hline
\end{tabular}

Os resultados apresentados mostram que a adição de microssílica ao concreto aumentou significativamente a resistência à compressão, tanto a 7 dias quanto a 28 dias para as três adições realizadas. Na adição de $15 \%$ observa-se uma redução em relação à adição de $9 \%$. Acredita-se que essa redução ocorreu em função do aumento de finos na composição do concreto.

Na Tabela 4 apresenta-se ainda a variação percentual entre os traços, demonstrado que o traço de $9 \%$ teve um aumento superior a $100 \%$ da resistência do traço de referência e sendo superior inclusive a resistência à compressão de $25 \mathrm{MPa}$ adotada inicialmente para a definição do traço do concreto. A partir da Tabela 4 foram realizadas análises gráficas dos ensaios de compressão axial com as respectivas datas de 7 dias e 28 dias. A Figura 3 e a Figura 4 apresentam as tabelas com os resultados do ensaio à compressão aos 7 dias para as dosagens ensaiadas.

A partir dos gráficos apresentados nas Figuras 5 e 6, constata-se que ocorre um incremento de resistência à compressão quando é adicionado até $9 \%$ de microssílica, havendo uma queda quando adiciona-se $15 \%$ de microssílica. Esse comportamento é possível de ser observado a partir da linha de tendência exponencial de 4 grau que foi traçada, onde estima-se que o valor ótimo de microssílica gira em torno de $9 \%$ a $10 \%$, o que vai de encontro com o comportamento apresentado nos trabalhos de Wang et al. (2021) e Sumathi e Saravana (2022) em que para os concretos convencionais e concreto de ultra-alta-resistência, foram sugeridos uma faixa de adição de microssilica de $7 \%$ a $13 \%$.

Persp. Online: exatas \& eng., Campos dos Goytacazes, 34(11) 01-17-2021

https://ojs3.perspectivasonline.com.br/ 


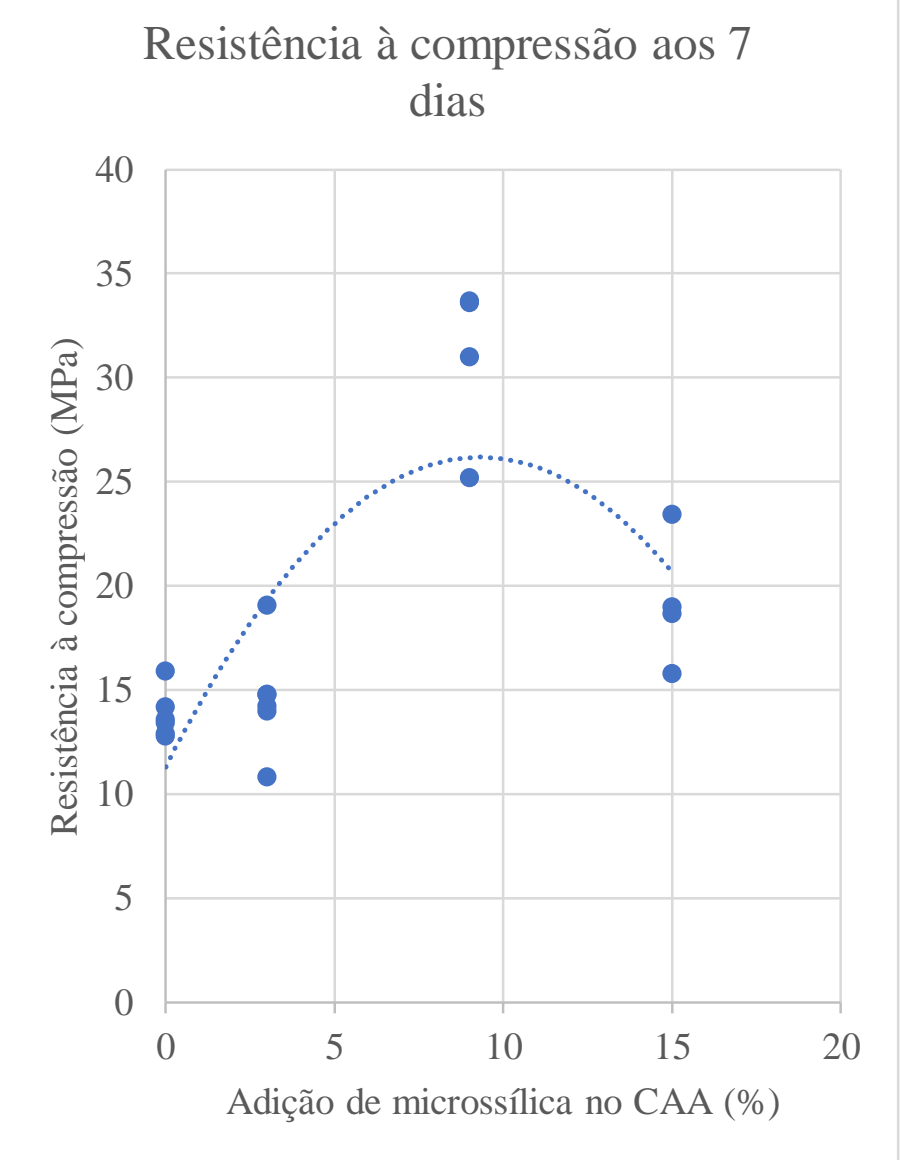

Figura 5: Resistência à compressão após 7 dias

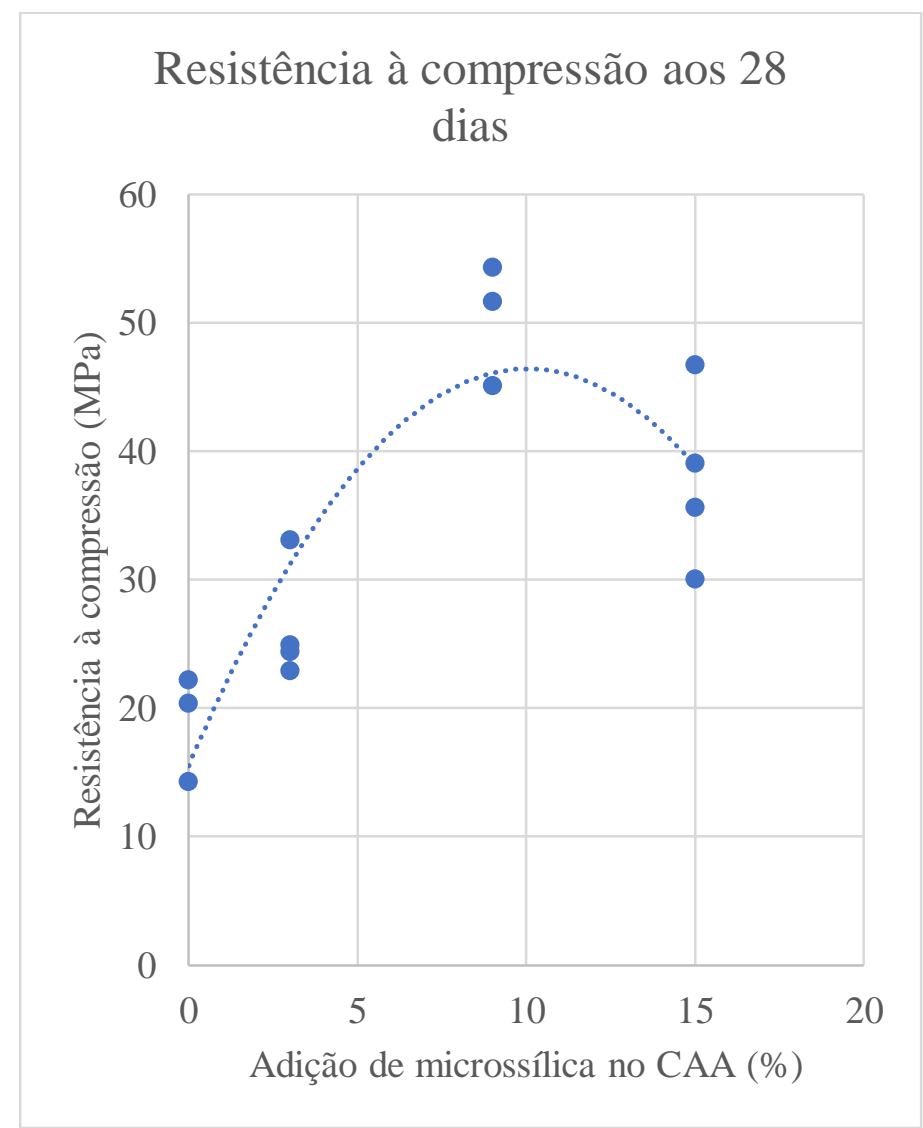

Persp. Online: exatas \& eng., Campos dos Goytacazes, 34(11) 01 -17-2021 https://ojs3.perspectivasonline.com.br/ 
Figura 6: Resistência à compressão após 28 dias

\subsubsection{Compressão diametral}

$\mathrm{Na}$ tabela 5 são apresentados os resultados dos ensaios de compressão diametral realizados nos corpos de provas dos concretos auto-adensáveis para as idades de 7 e 28 dias.

Para os concretos de $0 \%$ e $3 \%$ não foi possível determinar os valores da resistência à tração indireta com 7 dias em função de manutenção no equipamento de ensaio, com isso os mesmos não serão apresentados. Analisando os resultados de 28 dias observa-se que o comportamento foi similar à compressão axial, onde ocorreu um aumento da resistência até a adição de $9 \%$ e posteriormente uma queda quando adiciona-se $15 \%$ de microssílica.

Tabela 5 - Resultado à compressão diametral (tração indireta) à 7 e 28 dias

\begin{tabular}{lll}
\hline Traço & $\begin{array}{l}\text { Resistência à } \\
\text { Compressão } \\
\text { média (MPa) } \\
28 \text { dias }\end{array}$ & $\begin{array}{l}\text { Diferença (\%) em } \\
\text { relação ao traço } \\
\text { de referência } \\
\text { 28 dias }\end{array}$ \\
\hline CAA0 & 2,27 & 0,00 \\
CAA3 & 3,27 & $44,05 \%$ \\
CAA9 & 4,66 & $105,28 \%$ \\
CAA15 & 2,98 & $31,27 \%$ \\
\hline
\end{tabular}

A partir da Tabela 5 foi realizada análise gráfica dos ensaios de compressão diametral para os 28 dias. A Figura 7 representa essa análise. 


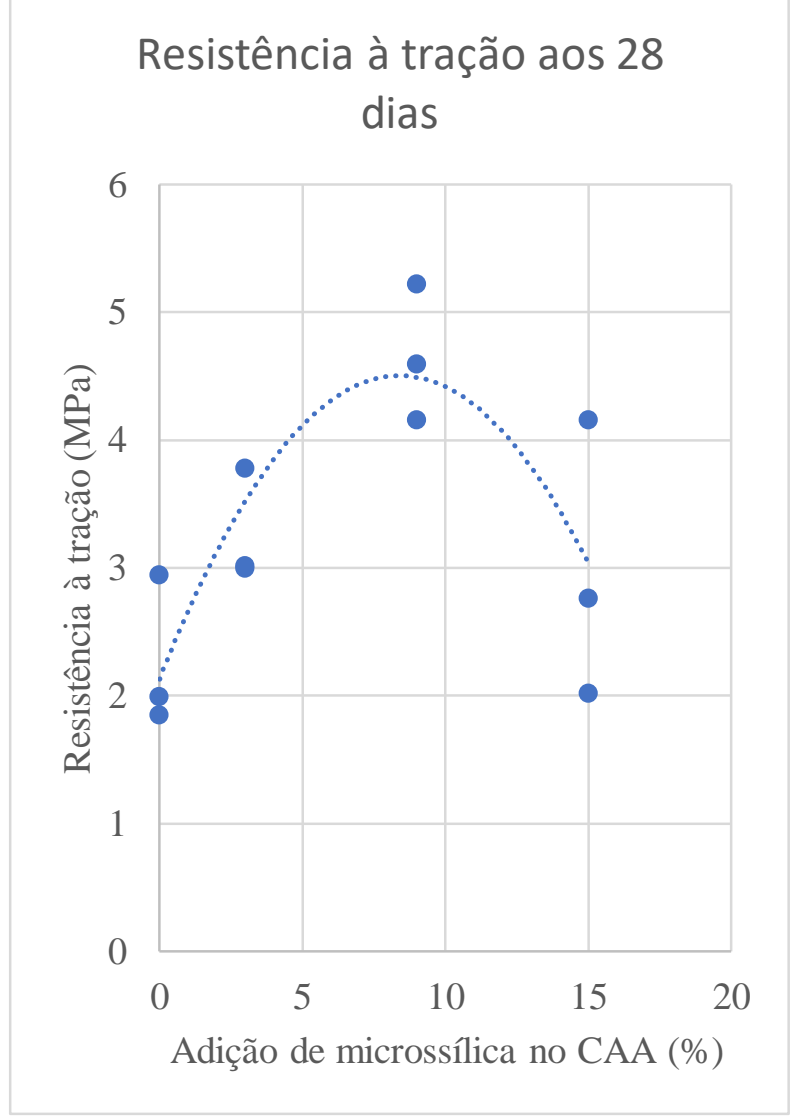

Figura 7: Tração 28 dias

Constatou-se que houve um incremento de resistência à tração, saindo em torno de 2 $\mathrm{MPa}$, aumentando significativamente até em torno de 4,67 $\mathrm{MPa}$, havendo posteriormente uma queda. De acordo os dados obtidos no trabalho de Wang et al. (2021) e Sumathi e Saravana (2022), a resistência à tração não teve um aumento de cerca de $100 \%$, com a adição de $12 \%$ de microssilica. Esse aumento na resistência à tração subiu proporcional ao aumento da resistência à compressão.

\subsubsection{Densidade}

A microssílica atua como microfiller no concreto devido à pequena dimensão de suas partículas. Na Figura 8 é representado o gráfico de densidade para os concretos produzidos, com o intuito de avaliar a influência da adição de microssílica na sua densidade. A densidade média do concreto auto-adensável produzido no traço de referência CAA0 foi de $2.300 \mathrm{~kg} / \mathrm{m}^{3}$ com um desvio padrão de $43,11 \mathrm{~kg} / \mathrm{m}^{3}$.

Com a adição de microssílica é esperado aumento da densidade porque as partículas de microssílica são menores que as do cimento, o que as tornaria mais propícias para o preenchimento dos vazios entre as partículas do cimento no concreto. É possível observar no gráfico da Figura 6 que para o CAA3 a expectativa de aumento de densidade foi atingida, o concreto obteve densidade média de $2.342 \mathrm{~kg} / \mathrm{m}^{3}$, com desvio padrão de $56,67 \mathrm{Kg} / \mathrm{m}^{3}$. Porém é importante ressaltar que o CAA3 obteve a maior dispersão de valores de densidade, obtendo o menor $\left(2.236 \mathrm{~kg} / \mathrm{m}^{3}\right)$ e o maior valor de densidade $\left(2.418 \mathrm{~kg} / \mathrm{m}^{3}\right)$ dentre todos os traços.

Persp. Online: exatas \& eng., Campos dos Goytacazes, 34(11) 01 -17-2021 


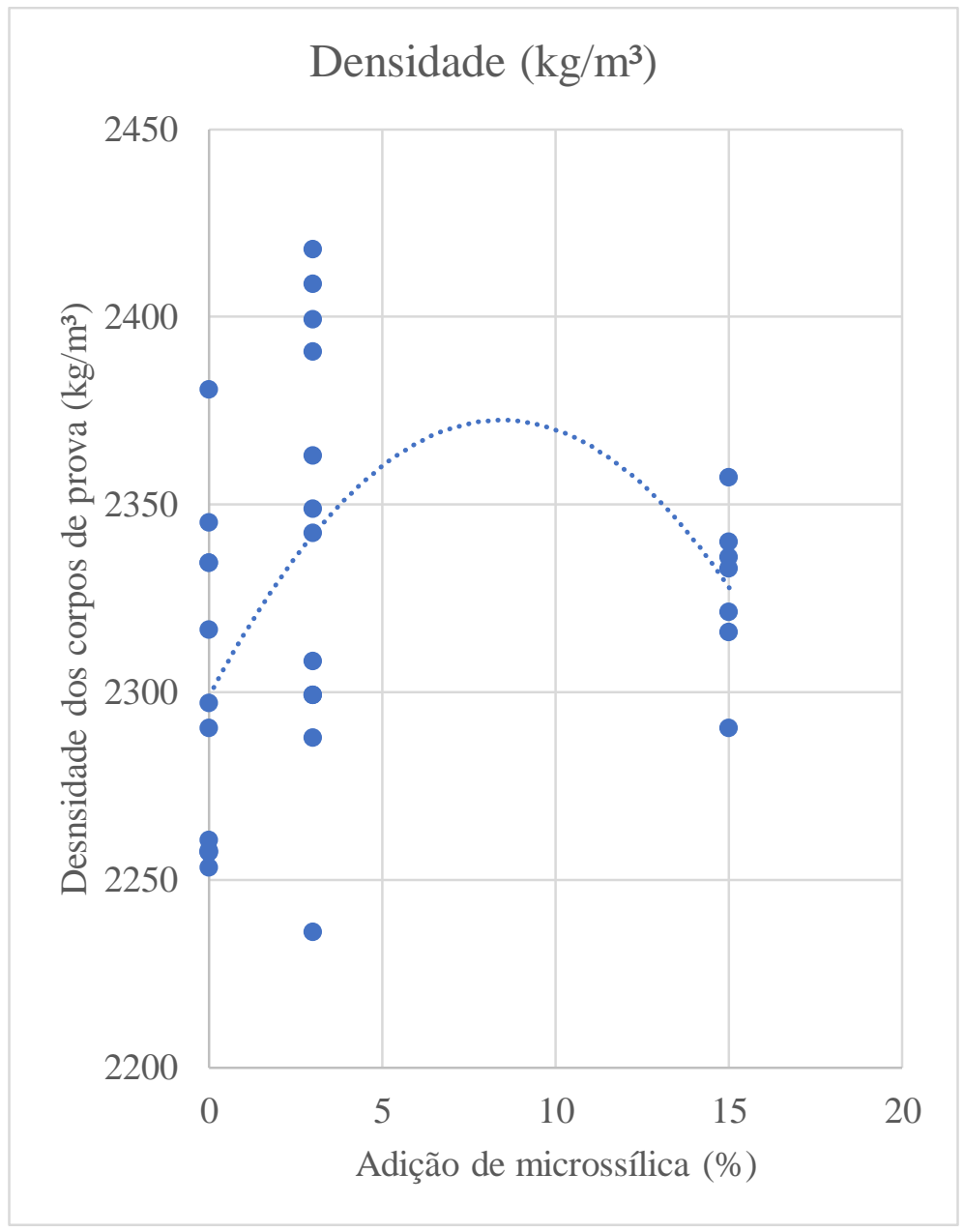

Figura 8 - Gráfico de densidade do CAA

O concreto CAA15 obteve densidade média de $2.327 \mathrm{~kg} / \mathrm{m}^{3}$ com desvio padrão de $21,12 \mathrm{~kg} / \mathrm{m}^{3}$, e, portanto, também atendeu a expectativa de acréscimo no valor da densidade com a adição de microssílica. Pode-se observar que os valores de densidade para o CAA15 $\left(2.290,65 \mathrm{~kg} / \mathrm{m}^{3}\right.$ a $\left.2.357,34 \mathrm{~kg} / \mathrm{m}^{3}\right)$ estão dentro do intervalo de valores de densidade obtidos para o CAA0 $\left(2.253,47 \mathrm{~kg} / \mathrm{m}^{3}\right.$ a $\left.2.380,81 \mathrm{~kg} / \mathrm{m}^{3}\right)$. Por esse motivo é válido ressaltar que os resultados para esse traço obtiveram menor dispersão de valores em relação ao traço de referência, o que proporciona um valor de densidade média maior. Essa densidade maior também foi observado nos trabalhos de Wang et al. (2021) e Sumathi e Saravana (2022).

\section{CONCLUSÕES}

Por meio da análise das quatro dosagens de concreto autoadensavel com adição de $0 \%$, $3 \%, 9 \%$ e $15 \%$ de microssílica, confeccionadas para o presente estudo, pode-se observar que os resultados obtidos quanto às resistências mecânicas foram coerentes com os resultados apresentados nos estudos de concreto convencional com adição de microssílica.

Pode-se, então, concluir que a adição de microssílica gera o mesmo comportamento tanto no concreto convencional quanto no concreto autoadensável. Portanto, para o concreto autoadensável com adição de microssílica pode-se utilizar como referência os mesmos intervalos ideais e o mesmo valor máximo de adição de microssílica que foram definidos através de experimentos pelos autores Malhotra e Mehta (1996), Wang et al. (2021) e Sumathi e Saravana (2022).

Persp. Online: exatas \& eng., Campos dos Goytacazes, 34(11) 01 -17-2021 
A resistência mecânica à compressão e à tração aos 28 dias foi consideravelmente maior nos concretos com adição de microssílica, sendo que o traço CAA9 obteve os resultados mais altos de resistência à compressão $(49,50 \mathrm{MPa})$ e de resistência à tração $(4,67$ $\mathrm{MPa})$ em relação aos demais traços ensaiados. Isso era esperado de acordo com os experimentos da literatura estudada, já que está dentro do intervalo de $7 \%$ a $10 \%$ de adição de microssílica.

Esse aumento de resistência pode ser explicado pela utilização da microssílica que coopera para conservação da resistência mecânica em matrizes cimentícias pela elevada atividade pozolânica. É importante ressaltar que a adição de microssílica deverá sempre ser controlada, pois havendo uma adição desbalanceada, poderá acarretar consequências, como por exemplo a diminuição de resistência , visto que o objetivo da microssílica é preencher os vazios tornando o concreto mais denso, diminuindo a permeabilidade e aumentando a vida útil e resistência principalmente em ambientes agressivos.

O resultado de espalhamento obtido no ensaio de Slump Flow para o traço CAA15 não foi satisfatório e não atendem às condições mínimas para a devida utilização e funcionalidade do concreto autoadensável. Apesar disso, os resultados mecânicos foram satisfatórios e estão de acordo com o esperado.

Por fim, assim como esperado devido a microssílica se comportar como microfiler no concreto, a densidade do concreto aumenta com a adição de microssílica. Esse aumento foi observado especialmente no concreto auto adensável com adição de $3 \%$ de microssílica que obteve acréscimo de $1,83 \%$ em relação a densidade do concreto auto adesnsável de referência sem adição de microssílica.

\section{Agradecimentos}

Os autores agradecem ao Programa de Educação Tutorial da Engenharia Civil - PET CIVIL - PUC Minas pelo apoio para desenvolvimento deste trabalho e a empresa MINASLIGAS pelo fornecimento das Microssílicas.

\section{REFERÊNCIAS}

AÏTCIN, P.C. High-Performance Concrete. Québec: Université de Sherbrooke, 1998.

ANJOS, M. A. S. ; FONSECA, T. V.; MENDONÇA, L. K. M e PEDERNEIR, C. M., Avaliação da ativiadade pozolânica de Microssílica cinza densificada de não densificada, HOLOS, Ano 32, Vol. 7, 2016 DOI: 10.15628/holos.2016.2706

ASSOCIAÇÃO BRASILEIRA DE NORMAS TÉCNICAS-ABNT. NBR 13956: Sílica ativa para uso com cimento Portland em concreto, argamassa e pasta. Parte 1: Requisitos. Rio de Janeiro, 2012.

- NBR 15823-1: Concreto Autoadensável. Parte 1: Classificação, controle e recebimento no estado fresco. Rio de Janeiro.2017.

Persp. Online: exatas \& eng., Campos dos Goytacazes, 34(11) 01 -17-2021

https://ojs3.perspectivasonline.com.br/ 
NBR 15823-2: Concreto Autoadensável Parte 2: Determinação do espalhamento, do tempo de escoamento e do índice de estabilidade visual - Método do cone de Abrams. Rio de Janeiro.2017.

NBR 5739: Concreto - Ensaio de compressão de corpos de prova cilíndricos. Rio de Janeiro.2018.

CARMO, J. B. M. Análise comparativa do desempenho de concretos compostos por sílica ativa e metacaulim face à resistência mecânica è à viabilidade econômica. 2006. $136 \mathrm{f}$. Dissertação (Mestrado) - Curso de Engenharia e Ciência dos Materiais, Programa de Pósgraduação em Engenharia - Pipe, Universidade Federal do Paraná, Curitiba, 2006.

DA SILVA, R. R. C., BONFIM, L. H. de S. (2019). Análise do comportamento mecânico de concreto com diferentes tipos de adição de fibras através da propagação de onda de ultrassom. Exatas \& Engenharias, v. 9, n.25, p. https://doi.org/10.25242/885X92520191748

P.L. Domone, Self-compacting concrete: An analysis of 11 years of case studies, Cement and Concrete Composites, v. 28, Issue 2, 2006, p. 197-208, ISSN 0958-9465, https://doi.org/10.1016/j.cemconcomp.2005.10.003

GOlOZEWSKA, M. GIERGICZNY, Z. Study of the Properties of Blended Cements Containing Various Types of Slag Cements and Limestone Powder, Materials, v. 14 n. 20 p. 6072,2021

KLUG, Y.; HOLCHMACHER, K. Comparison of the hardened properties of selfcompacting and normal vibrated concrete. Rheological measurements on selfcompacting fibre reinforced concrete. In: Thrird International Symposium on Selfcompacting concrete. 2003, Reykjavik, p. 596-605.

MALHOTRA, V.M.; MEHTA, P.K. Pozzolanic and cementitious materials. Advances in Concrete Technology, v. 1, Gordon and Breach Publishers, 1996.

MENDES, M.; BAUER, E.; SILVA, F.; Avaliação dos parâmetros de autoadensabilidade e de reologia do concreto autoadensável, Matéria (Rio J.) v. 22, n. 4, 2017, https://doi.org/10.1590/S1517-707620170004.0212

MEHTA, P.K. RAMACHANDRAN, V.S. Mineral Admixtures. In: Concrete admixtures handbook: properties, science, and technology. Noyes publications: Park ridge, 1984.

MOUSAVINEJAD, Seyed Hosein Ghasemzadeh; SAMMAK, Moein, An assessment of the fracture parameters of ultra-high-performance fiber-reinforced geopolymer concrete (UHPFRGC): The application of work of fracture and size effect methods, Theoretical and Applied Fracture Mechanics, v.117, 2022, https://doi.org/10.1016/j.tafmec.2021.103157.

SABIR, B. B.. "High-strength condensed silica fume concrete." Magazine of Concrete Research v. 47, p. 219-226, 1995

Persp. Online: exatas \& eng., Campos dos Goytacazes, 34(11) 01 -17-2021

https://ojs3.perspectivasonline.com.br/ 
SALGADO, J., CARVALHO, S., \& CORDEIRO, B. Alvenaria de blocos de encaixe sem $\begin{array}{llllll}\text { argamassa. Exatas } & \& & \text { Engenharias, v.9 } & \mathrm{n}^{\mathrm{o}} & 25 . & 2019\end{array}$ https://doi.org/10.25242/885X92520191810

SANTOS, P. S. Ciência e tecnologia de argilas. $2^{\mathrm{a}}$ ed. São Paulo: Edgard Blücher, 3v, 1992

SUMATHI, A.; SARAVANA RAJA MOHAN, K. Effect of Silica Fume and Steel Fiber on Mechanical Characteristics of High-Strength Concrete. In: Sustainable Cities and Resilience. Springer, Singapore, 2022. p. 419-431.

RILEM TECHNICAL REPORTS. Final Report: Siliceous by-products for use in concrete. Materials and Structures, v. 21, n. 121, 1988. p. 69-80

TROYAN, Vyacheslav; KINDRAS, Bogdan. Increasing the Crack Resistance of HighStrength Self-compacting Concrete. Technology audit and production reserves, v. 1, n. 1, p. 57, 2021.

TUTIKIAN, B. Concreto auto-adensável. $1^{\text {o }}$ ed. São Paulo:Pini, 2008.

WANG, Q., YAO, B., HE, J., HE, X., e HO, J. C. M. Impact of condensed silica fume on splitting tensile strength and brittleness of high strength self-compacting concrete. Structural Concrete. (2021) https://doi.org/10.1002/suco.202000652 